\title{
Serum Apo A-1 and Its Role as a Biomarker of Coronary Artery Disease
}

Salma Rahim ${ }^{1}$, Hafez Mohammad A. Abdullah ${ }^{2}$, Yousaf Ali ${ }^{3}$, Uzma I. Khan ${ }^{2}$, Waqas Ullah ${ }^{4}$, Muhammad A. Shahzad ${ }^{5}$, Muhammad Waleed ${ }^{2}$

1. Biochemistry, Bacha Khan Medical College 2. Internal Medicine, Khyber Teaching Hospital 3. Public Health, The Aga Khan University 4. Internal Medicine, University of Arizona 5. Internal Medicine, Hayatabad Medical Complex

$\square$ Corresponding author: Hafez Mohammad A. Abdullah, dr.ammarabdullah@gmail.com Disclosures can be found in Additional Information at the end of the article

\section{Abstract}

\section{Objectives}

To evaluate the role of apolipoprotein (Apo A-1) as a biomarker of coronary artery disease (CAD) and its comparison with the traditional marker high-density lipoprotein (HDL).

\section{Methodology}

One hundred patients proven to have coronary artery disease by angiography were recruited and their serum biomarkers were compared with 100 normal individuals adjusted for age and sex.

\section{Result}

The mean +/-standard deviation (SD) value of plasma Apo A-1 levels in the normal individuals were observed to be $207.42+/-41.35(\mathrm{mg} / \mathrm{dL})$ against $90.69+/-20.77(\mathrm{mg} / \mathrm{dL})$ in the cardiac patients. On the other hand the serum HDL levels were $52.93+/-33.58(\mathrm{mg} / \mathrm{dL})$ in the normal individuals and $37.86+/-23.19(\mathrm{mg} / \mathrm{dL})$ in the cardiac patients. Both of these differences were statistically significant $(\mathrm{p}<0.001)$. For Apo A-1, a large proportion of patients $(85 \%)$ were found to be in the abnormal range when compared to the control group in which only $7 \%$ had an abnormal value. For HDL, a majority (70\%) of the cardiac patients had abnormal values while $40 \%$ of the normal individuals also had abnormal values. The sensitivity of Apo A-1 for detecting CAD was $85 \%$, while for HDL, it was only $69 \%$. Similarly, the specificity of Apo A-1 for detecting CAD was $93 \%$, while for HDL, it was $60 \%$. When plotted on a receiver operating characteristic (ROC) curve, Apo A-1 had a much larger area under the curve when compared to HDL.

Received 07/14/2016 Review began 07/19/2016 Review ended 12/14/2016 Published 12/24/2016

\section{(c) Copyright 2016}

Rahim et al. This is an open access article distributed under the terms of the Creative Commons Attribution License CC-BY 3.0., which permits unrestricted use, distribution, and reproduction in any medium, provided the original author and source are credited.

\section{Conclusion}

This study suggests that Apo A-1 may, in fact, be more sensitive than HDL as a predictor of CAD. However, to completely elucidate its role as a biomarker, to set target serum levels and to increase its clinical use, further studies are required.

Categories: Cardiology

Keywords: apo a-1, coronary artery disease, hdl 


\section{Introduction}

Plasma cholesterol levels are important predictors of coronary artery disease (CAD) [1-2]. Various plasma cholesterol parameters like HDL, LDL levels, and indices like total cholesterol/HDL and LDL/HDL have been used as predictors of CAD [3-4]. It has been observed that plasma Apo A-1 levels, the major protein of HDL, may also be a reliable marker of CAD [57]. Many studies have suggested that plasma Apo A-1 and apolipoprotein (Apo B) levels may, in fact, be more accurate predictors of CAD [8-11], especially in those patients having low or normal LDL cholesterol levels [12]. In fact, some studies suggest that the ratio of plasma Apo B to plasma Apo A-1 may be the most accurate predictor for $C A D$ [9-12]. However, there are still some limitations to the usage of Apo A-1 or the Apo B/Apo A-1 ratio and it still remains to be seen what additional information plasma Apo A-1 levels can provide that plasma HDL levels cannot [9].

Coronary artery disease is reported to be the leading cause of morbidity and mortality worldwide and as such it is an important public health concern [13-14]. Early diagnosis and treatment can prevent many cases of acute coronary syndrome. Besides its mortality benefit, a good screening test for coronary artery disease can significantly reduce the human and financial resources dedicated to the management of coronary artery disease related morbidity and mortality. Studies have pointed to a wide spectrum of genetic and acquired risk factors associated with CAD [14]. However, whatever the risk factors are, there is usually an underlying defect in cholesterol homeostasis that leads to coronary artery atherosclerosis, which eventually leads to coronary artery disease. The most important factor is the balance between the pro-atherogenic factors low-density lipoprotein (LDL) and Apo B and the anti-atherogenic factors HDL and Apo A-1 levels. LDL, along with its major component Apo B, is tasked with taking hepatic cholesterol to tissues to fulfill their needs, and HDL and Apo A-1 bring back any excess cholesterol deposited in the blood vessels to the liver for excretion.

Apo A-1 is the major protein component of high-density lipoprotein cholesterol (HDL-C). It is also initially a part of chylomicrons that are released by enterocytes, but it is then transferred back onto HDL-C. It has a molecular weight of $28.1 \mathrm{kDa}$ and is encoded by the apolipoprotein A1 (Apo A-1) gene. It plays an important role in cholesterol metabolism, along with HDL-C. The main function of HDL-C is to take up cholesterol in tissues and direct it back to the liver for excretion through the bile. Cholesterol cannot be metabolized and used as a source of energy in the human body, so excretion through bile is the only way the body can get rid of excess cholesterol after the body's requirements have been met. Apo A-1 helps HDL in this task. Apo A-1 also activates lecithin-cholesterol acyltransferase (LCAT), the enzyme present on HDL that esterifies the cholesterol picked up by HDL and, hence, renders it lipid-soluble so that it can be sequestered deep within the HDL particles, ensuring that the HDL particles do not lose the cholesterol esters again. The sequestered cholesterol esters can then be taken up by the liver, along with the HDL particles. Apo A-1 has several other important functions as well and its deficiency and mutations have been implicated in various diseases ranging from a hypercoagulable state to Alzheimer's disease and amyloidosis [15-16]. Apo A-1 is reported to have a stabilizing effect on prostacyclin and may have an anti-clotting role to play [17]. A recent study suggested Apo A-1 has anti-inflammatory and anti-tumorigenic effects, in addition to its cardioprotective effects [18]. It also has a negative correlation with insulin resistance [19]. HDL deficiency states may occur due to defects in the Apo A-1 protein, including Tangier's disease. Polymorphisms in the Apo A-1 gene have led to the discovery of conditions with a greatly increased risk of developing early atherosclerosis and CAD [15]. However, in some cases, the polymorphic forms may be protective against CAD.

The serum level of HDL has traditionally been considered to be an important biomarker of CAD; however, recent studies have indicated that in some cases higher HDL levels may not always be protective [20]. One interesting observation mentioned by a meta-analysis of eight statin trials 
was that a rise in HDL after statin therapy had no significant cardiovascular benefit, whereas a rise in Apo A-1 resulted in a significant reduction of cardiovascular events [21]. This has challenged the long-held concept that high HDL levels always reduce the risk of CAD. Also, the serum lipid and cholesterol levels have been unable to explain the prevalence of CAD in patients with a normal lipid profile [22]. Considering the research already mentioned indicating the superiority of Apo A-1 and Apo B as biomarkers, it is now genuinely thought that these proteins can replace HDL and LDL as the primary markers of CAD. Various studies have already indicated that low Apo A-1 is an independent risk factor for CAD [23]. It is reported also to have a beneficial effect on non-ischemic heart failure through its anti-inflammatory effect [24]. It is also reported to be an early marker of CAD and may be helpful in the screening of younger patients [25]. Apo A-1 is also suggested to be a marker of the severity of coronary artery obstruction [26]. This study was carried out to find the correlation between CAD and serum Apo A-1 and its utility as a biomarker of CAD as compared to HDL. Informed consent was obtained from all patients for this study.

\section{Materials And Methods}

This research was conducted at the Postgraduate Medical Institute (PGMI) Lady Reading Hospital (LRH) Peshawar, after the approval of the Ethics Committee of PGMI. Two hundred subjects were recruited. One hundred of them were cardiac patients who underwent angiography and were confirmed to be having CAD. The remaining 100 were individuals with no atherosclerosis on angiography. The subjects were adjusted for age, and various parameters and serum biomarkers, including the fasting lipid profile, Apo A-1, Apo B, serum leptin, and serum glucose levels, were measured. The lipid profile was determined by the calorimetric method using a kit provided by Roche, Switzerland. Apo A-1 and Apo B were determined by the immunoturbidimetric method utilizing kits supplied by Roche, Switzerland.

\section{Results}

A total of $200(n=200)$ subjects were included in the study. One hundred were CAD patients, proven by angiography to have significant atherosclerosis and placed in the patient group, while the other 100 subjects were individuals of a similar age group, sex, race, geographic location, and socioeconomic status with no atherosclerosis on angiography placed in the control group. Various parameters were measured and expressed as mean+SD. Then the sensitivity, specificity, positive predictive values, negative predictive values, and ROC curves for Apo A-1 and HDL were derived.

The biochemical characteristics of the cardiac patients and the control group are summarized in Table-1. It shows that there is a very significant difference in serum Apo A-1 levels in the cardiac patients and the normal healthy individuals. The mean+SD of plasma Apo A-1 levels in the normal individuals was observed to be $207.42+/-41.35$ (mg/dL), against $90.69+/-20.77$ $(\mathrm{mg} / \mathrm{dL})$, in the cardiac patients. On the other hand, the mean +/- SD serum HDL levels were $52.93+/-33.58(\mathrm{mg} / \mathrm{dL})$ in the healthy individuals and $37.86+/-23.19(\mathrm{mg} / \mathrm{dL})$ in the cardiac patients. Both of these results show a statistically significant $(\mathrm{p}<0.01)$ difference between the levels of both Apo A-1 and HDL in coronary artery disease patients when compared with the healthy individuals (Table 1). 


\section{Cureus}

\begin{tabular}{|c|c|c|}
\hline & Mean & SD +/- \\
\hline Mean Apo A-1 level in Diseased & $90.69 \mathrm{mg} / \mathrm{dl}$ & $20.77668 \mathrm{mg} / \mathrm{dl}$ \\
\hline Mean Apo A-1 level in Normal & $202.2 \mathrm{mg} / \mathrm{dl}$ & $50.64812 \mathrm{mg} / \mathrm{dl}$ \\
\hline Mean HDL level in Diseased & $35.448 \mathrm{mg} / \mathrm{dl}$ & $16.81668 \mathrm{mg} / \mathrm{dl}$ \\
\hline Mean HDL level in Normal & $41.50 \mathrm{mg} / \mathrm{dl}$ & $9.338324 \mathrm{mg}$ \\
\hline
\end{tabular}

\section{TABLE 1: Biochemical characteristics of cardiac patients and controls}

\section{$2 \times 2$ table for Apo A-1}

Apo A-1 shows higher sensitivity and specificity than HDL. The sensitivity and specificity of Apo A-1 in detecting diseased cases was calculated to be $85 \%$ and $93 \%$, respectively, as compared to that of HDL in which case the sensitivity and specificity were $69 \%$ and $60 \%$, respectively. The positive and negative predictive values of Apo A-1 were 92\% and 86\%, respectively, as compared to that of HDL which is 63\% and 66\%, respectively (Tables 2-3).

$\begin{array}{lllc} & \text { Diseased } & \text { Not Diseased } & \text { Total } \\ \text { Positive } & 85 & 7 & 92 \\ \text { Negative } & 15 & 93 & 200 \\ \text { Total } & 100 & 100 & 85 \% \\ \text { Sensitivity } & & 93 \% & 92.3913 \\ \text { Specificity } & & 86.1111\end{array}$

TABLE 2: 2x2 table for Apo A-1 and sensitivity, specificity, positive predictive value and negative predictive value for Apo A-1 


\section{Cureus}

$2 \times 2$ table for HDL

$\begin{array}{llll} & \text { Diseased } & \text { Not Diseased } & \text { Total } \\ \text { Positive } & 69 & 40 & 109 \\ \text { Negative } & 31 & 60 & 91 \\ \text { Total } & 100 & 100 & 200 \\ \text { Sensitivity } & & 69 & \\ \text { Specificity } & & 60 & \\ \text { Positive predictive } & & 63.30275 & \\ \text { Negative predictive } & & 65.93407 & \end{array}$

TABLE 3: 2x2 table for HDL and sensitivity, specificity, positive predictive value and negative predictive value for HDL

ROC curve analysis of both the tests also showed a significant difference. In the case of Apo A1 the area under the curve as determined by its ROC curve was 0.94 while in the case of HDL the area under the curve of ROC curve turned out to be 0.70 (Table 4) (Figures 1-2). 


\section{Cureus}

\section{ROC Curve}

Apo A-1

\section{Cut off Value}

0

40

80

120

160

200

240

280

320

100

True +

AUC

0

0

2

0.0048

22

0.0242

99

0.0198

99

0.3762

99

0.3383

100

0.09

100

0.09

100

Area under the curve

0.9433

ROC Curve

HDL

Cut off Value

False +

True +

AUC

0

0

0

0

15

0

2

0.0231

30

11

40

0.3008

45

58

88

0.35685

60

97

95

0.0285

75

100

95

0

90

100

96

0

105

100

99

0

120

100

100

Area under the curve

0.70925

TABLE 4: ROC curves for Apo A-1 and HDL 


\section{Cureus}

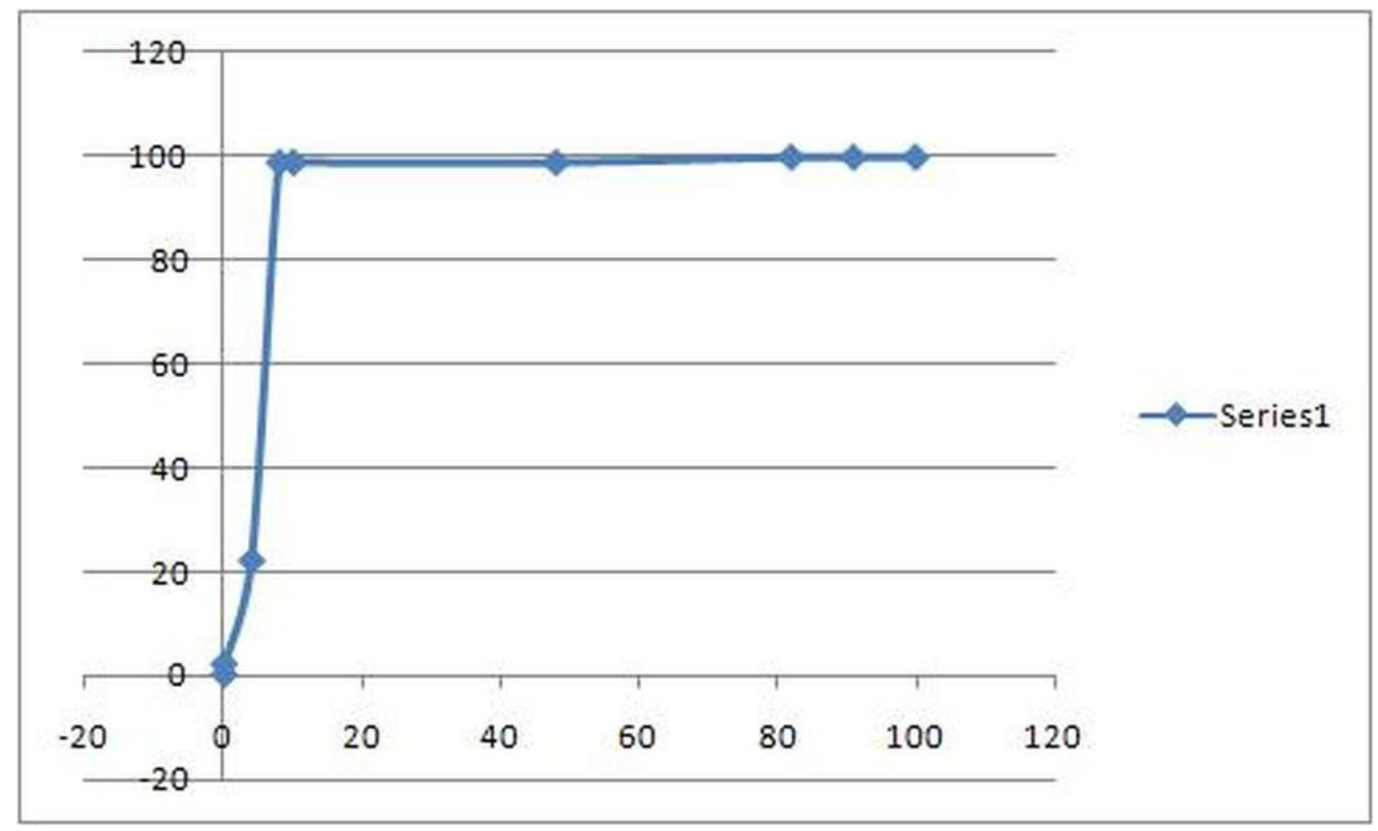

FIGURE 1: ROC curve for Apo A1

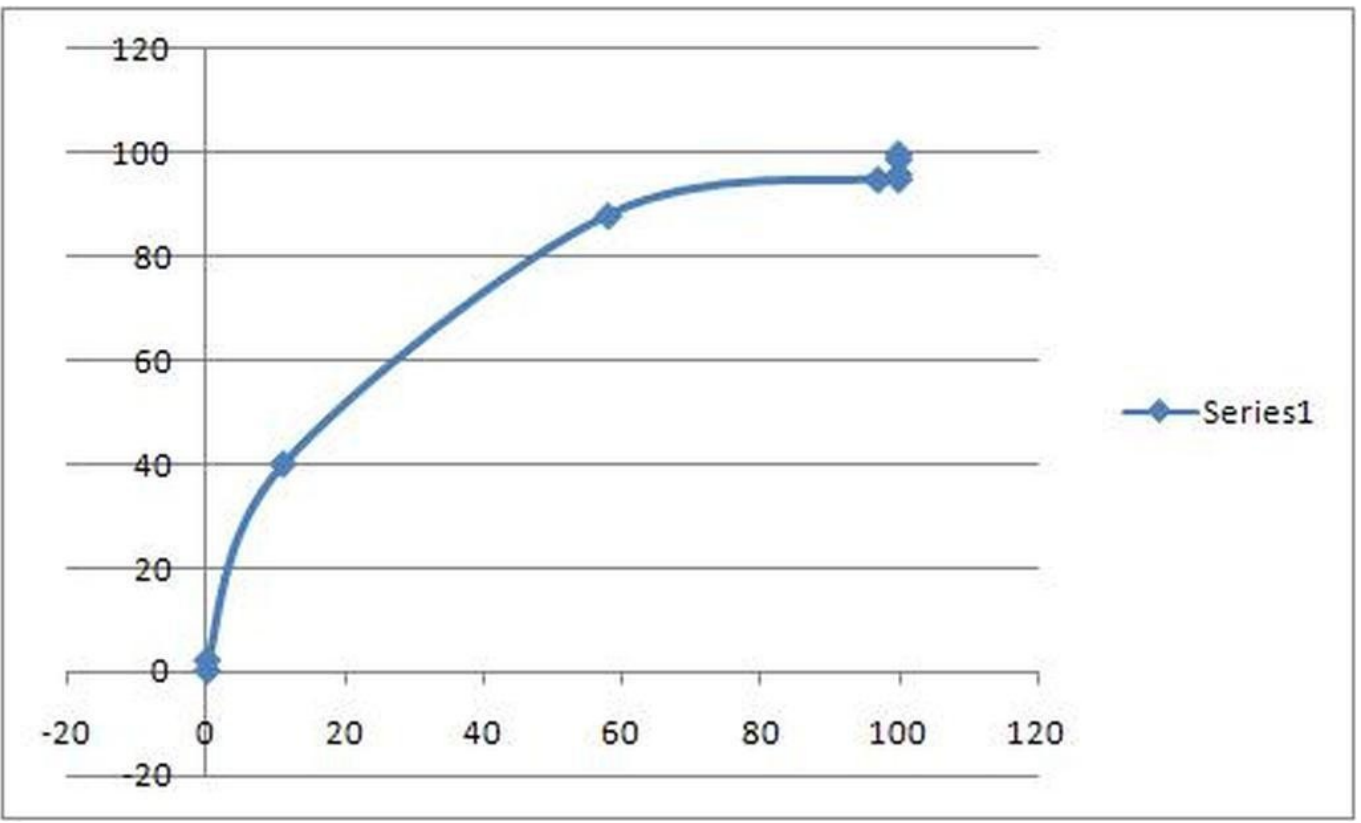

FIGURE 2: ROC curve for HDL

Though Apo A-1 gave us higher sensitivity and specificity as compared to HDL, we can also take the advantage of combined screening with multiple tests. In our study simultaneous screening with Apo A-1 and HDL increased the sensitivity level to 96\% (Table 5). Specificity was also increased to $96 \%$ by multi-stage screening with Apo A-1 followed by HDL (Table 6 ). 


\section{Cureus}

\section{Simultaneous screening with Apo A-1 and HDL}

$2 \times 2$ table for Apo A-1

$\begin{array}{llll} & \text { Diseased } & \text { Not Diseased } & \text { Total } \\ \text { Positive } & 96 & 43 & 139 \\ \text { Negative } & 4 & 57 & 61 \\ \text { Total } & 100 & 100 & 200 \\ & & \text { Sensitivity } & 96 \\ & & \text { Specificity } & 57\end{array}$

TABLE 5: Simultaneous screening with Apo A-1 and HDL

Multi stage screening with Apo A-1 and HDL

$2 \times 2$ table for Apo A-1

$\begin{array}{llll} & \text { Diseased } & \text { Not Diseased } & \text { Total } \\ \text { Positive } & 58 & 4 & 62 \\ \text { Negative } & 42 & 96 & 138 \\ \text { Total } & 100 & 100 & 200 \\ & & \text { Sensitivity } & 58 \\ & & \text { Specificity } & 96\end{array}$

TABLE 6: Multi-stage screening with Apo A-1 and HDL

\section{Discussion}

The results of our study showed a significant difference in the serum Apo A-1 levels of the coronary artery disease patients and normal controls. It showed that the serum Apo A-1 levels in normal healthy individuals was mean +/- SD 207.42 +/- 41.35 (mg/dL) and in cardiac patients was $90.69+/-20.77(\mathrm{mg} / \mathrm{dL})$ which is a very significant difference. A very large majority of healthy individuals (93\%) had their serum Apo A-1 levels within the normal range while most of the cardiac patients (85\%) had an abnormal serum Apo A-1 level. On the other hand the mean +/-SD serum HDL levels were 52.93 +/- 33.58 (mg/dL) in healthy individuals and 37.86 +/- 23.19 $(\mathrm{mg} / \mathrm{dL})$ in cardiac patients. Statistically, this difference is also significant. However, only $60 \%$ of the healthy individuals had HDL levels within the normal range and only $70 \%$ of the cardiac patients had an abnormal HDL level. Apo A-1 had a much higher sensitivity and specificity for detecting coronary artery atherosclerosis when compared with serum HDL levels. When plotted 
on ROC curve, Apo A-1 had a much higher area under the curve when compared with HDL. The ROC curve of Apo A- 1 showed the area under the curve to be 0.94 as against 0.70 for HDL, which suggested Apo A-1 as a more sensitive diagnostic test. Combining the two tests for better results in multi-stage screening did not add any significant amount of sensitivity; however, simultaneous screening with the two tests increased the sensitivity up to $96 \%$. These findings suggest that the serum Apo A-1 may be a more sensitive marker of coronary artery disease. In coronary artery disease patients, our study showed that Apo A-1 levels serve as a better diagnostic tool than HDL level as depicted by the higher sensitivity and specificity of Apo A-1 and a higher area under the curve on the ROC curve as compared to HDL.

\section{Conclusions}

Our study is consistent with many previous studies [12, 27-29], which, as discussed earlier, suggest that serum Apo A-1 may actually be more sensitive in predicting coronary artery disease as compared to serum HDL. Apo A-1 is also an early marker of CAD and is useful in estimating the risk of CAD in younger patients. Its use as a clinical tool should be increased for the better management and prevention of coronary artery disease. Its higher sensitivity may prove to reduce morbidity and mortality in the long run and, consequently, also reduce the financial burden posed by this disease. It is also more convenient to use as non-fasting samples are required as opposed to serum cholesterol levels.

The relatively smaller sample size of our study may have affected the degree of correlation of CAD with Apo A-1 and HDL due to a few outliers. Prospective studies with large cohorts are required to completely elucidate the correlation between serum Apo A-1 levels and CAD, to set the guidelines for the target plasma values, and increase its clinical use in the prevention of CAD.

\section{Additional Information \\ Disclosures}

Human subjects: Consent was obtained by all participants in this study. Lady Reading Hospital Peshawar issued approval 11189. This is to certify that ethical approval has been granted to Salma Rahim, PhD scholar, Institute of Chemical Sciences, for the project entitled "Evaluation of serum proteins as diagnostic markers in angiographically assessed cardiac patients". Animal subjects: All authors have confirmed that this study did not involve animal subjects or tissue. Conflicts of interest: In compliance with the ICMJE uniform disclosure form, all authors declare the following: Payment/services info: All authors have declared that no financial support was received from any organization for the submitted work. Financial relationships: All authors have declared that they have no financial relationships at present or within the previous three years with any organizations that might have an interest in the submitted work. Other relationships: All authors have declared that there are no other relationships or activities that could appear to have influenced the submitted work.

\section{References}

1. Castelli WP, Garrison RJ, Wilson PWF, Abbott RD, Kalousdian S, Kannel: Incidence of coronary heart disease and lipoprotein cholesterol levels: the Framingham study. JAMA. 1986, 256:2835-2838.

2. Gordon DJ, Rifkind BM: High density lipoprotein: the clinical implications of recent studies . N Engl J Med. 1989, 321:1311-16.

3. Stampfer MJ, Sacks FM, Salvini S, Willett WC, Hennekens CH: A prospective study of cholesterol, apolipoproteins, and the risk of myocardial infarction. N Engl J Med. 1991, 325:325-373.

4. Manninen V, Tenkanen L, Koskinen P, Huttunen JK, Manttari M, Heinonen OP, et al.: Joint 
effects of serum triglyceride and LDL cholesterol and HDL cholesterol concentrations on coronary heart disease risk in the Helsinki heart study: implications for treatment. Circulation. 1992, 85:37-45. 10.1161/01.CIR.85.1.37

5. Avogaro P, Bon GB, Cazzolato G, Quinci GB: Are apolipoproteins better discriminators than lipid for atherosclerosis?. Lancet. 1979, 1:901-903.

6. Durrington PN, Ishola M, Hunt L, Arrol S, Bhatnagar D: Apolipoproteins (a), AI, and B and parental history in men with early onset ischaemic heart disease. Lancet. 1988, 1:1070-1073.

7. Sedlis SP, Shechtman KB, Ludbrook PA, Sobel BE, Schonfeld G: Plasma apoproteins and the severity of coronary artery disease. Circulation. 1986, 73:978-986. 10.1161/01.CIR.73.5.978

8. Kwiterovich PO Jr, Coresh J, Smith H, Bachorik PS, Derby CA, Pearson TA: Comparison of the plasma levels of apolipoproteins B and A-1, and other risk factors in men and women with premature coronary heart disease. Am J Cardiol. 1992, 69:1015-21. 10.1016/00029149(92)90856-T

9. Sniderman $\mathrm{AD}$, Kiss RS: The strengths and limitations of the ApoB/ApoA-I ratio to predict the risk of vascular disease: a Hegelian analysis. Curr Atheroscler Rep. 2007, 9:261-5. 10.1007/s11883-007-0031-6

10. McQueen M, Hawken S, Wang X, Ounpuu S, Sniderman A, Probstfield J, et al.: Lipids, lipoproteins, and apolipoproteins as risk markers of myocardial infarction in 52 countries (the Inter heart study): a case-control study. Lancet. 2008, 9634:224-33. 10.1016/S01406736(08)61076-4

11. Liem AH, van de Woestijne AP, van Lennep HW R, Zwinderman AH, van der Steeg WA, Jukema JW: ApoB/A1 and LDL-C/HDL-C and the prediction of cardiovascular risk in statin-treated patients. Curr Med Res Opin. 2008, 24:359-64. 10.1185/030079907X253906

12. Walldius G, Jungner I, Holme I, Aastveit AH, Kolar W, Steiner E: High apolipoprotein B, low apolipoprotein A-I, and improvement in the prediction of fatal myocardial infarction (AMORIS study): a prospective study. Lancet. 2001, 358:2026-33. 10.1016/S01406736(01)07098-2

13. Santulli, G: Epidemiology of cardiovascular disease in the 21st century: updated numbers and updated facts. J Cardiovasc Dis. 2013, 1:1-2.

14. Yusuf S, Reddy S, Ounpuu S, Anand S: Global burden of cardiovascular diseases part I: general considerations, the epidemiologic transition, risk factors, and impact of urbanization. Circulation. 2001, 104:2746-53. 10.1161/hc4601.099487

15. Dastani Z, Dangoisse C, Boucher B, Desbiens K, Krimbou L, Dufour R, et al.: A novel nonsense apolipoprotein A-I mutation (apoA-I(E136X)) causes low HDL cholesterol in French Canadians. Atherosclerosis. 2006, 185:127-36. 10.1016/j.atherosclerosis.2005.05.028

16. Solomon A, Murphy C, Kestler D, Coriu D, Weiss D, Makovitzky J, et al.: Amyloid contained in the knee joint meniscus is formed from apolipoprotein A-I. Arthritis Rheumatol. 2006, 54:3545-50. 10.1002/art.22201

17. Yui Y, Aoyama T, Morishita H, Takahashi M, Takatsu Y, Kawai C: Serum prostacyclin stabilizing factor is identical to apolipoprotein A-I (apo A-I). A novel function of apo A-I. J Clin Invest. 1998, 3:803-7. 10.1172/JCI113682

18. Zamanian-Daryoush M, Lindner D, Tallant TC, Wang Z, et al.: The cardioprotective protein apolipoprotein A1 promotes potent anti-tumorigenic effects. J Biol Chem. 2013, 288:2123721252. 10.1074/jbc.M113.468967

19. Makaridze Z, Giorgadze E, Asatiani K: Association of the apolipoprotein B/apolipoprotein AI ratio, metabolic syndrome components, total cholesterol, and low-density lipoprotein cholesterol with insulin resistance in the population of Georgia. Int J Endocrinol. 2014, 2014:8. 10.1155/2014/925650

20. Benjamin F Voight, Gina M, et al.: Plasma HDL cholesterol and risk of myocardial infarction: a mendelian randomisation study. Lancet. 2012, 380:572-80. 10.1016/S0140-6736(12)60312-2

21. Boekholdt SM, Arsenault BJ, Hovingh GK, Mora S, Pedersen TR, Larosa JC, et al.: Levels and changes of HDL cholesterol and apolipoprotein A-I in relation to risk of cardiovascular events among statin-treated patients: a meta-analysis. Circulation. 2013, 128: 1504-12. 10.1161/CIRCULATIONAHA.113.002670

22. Hughes LO: Insulin, Indian origin and ischemic heart disease . Int J Cardiol. 1990, 26:1-4. 10.1016/0167-5273(90)90239-2

23. Barter PJ, Rye KA: The rationale for using apoA-I as a clinical marker of cardiovascular risk . J Intern Med. 2006, 259:447-54. 10.1111/j.1365-2796.2006.01647.x 


\section{Cureus}

24. Iwaoka M, Obata JE, Abe M, Nakamura T, Kitta Y, Kodama Y, et al.: Association of low serum levels of apolipoprotein A-I with adverse outcomes in patients with nonischemic heart failure. J Card Fail. 2007, 13:247-53. 10.1016/j.cardfail.2007.01.007

25. Srinivasan SR, Berenson GS: Serum apolipoproteins A-I and B as markers of coronary artery disease risk in early life: the Bogalusa heart study. Clin Chem. 1995, 41:159-64.

26. Y. Saez, M. Vacas, M. Santos, et al.: Relation of high-density lipoprotein cholesterol and apoprotein A1 Levels with presence and severity of coronary obstruction. ISRN Vasc Med. 2012, 2012:5. 10.5402/2012/451730

27. Walldius G, Jungner I: Apolipoprotein A-I versus HDL cholesterol in the prediction of risk for myocardial infarction and stroke. Curr Opin Cardiol. 2007, 22:359-67.

10.1097/HCO.0b013e3281bd8849

28. Luc G, Bard JM, Arveiler D, Ferrieres J, Evans A, Amouyel P, et al.: Lipoprotein (a) as a predictor of coronary heart disease: the PRIME Study. Atherosclerosis. 2002, 163:377-84. 10.1016/S0021-9150(02)00026-6

29. Agoston-Coldea L, Zdrenghea D, Pop D, Craciun A, Rusu ML, Mocan T: Apolipoproteins A-I and B-markers in coronary risk evaluation. Rom J Intern Med. 2007, 45:251-258. 